\title{
Intra-Scrotal Extra-Testicular Leiomyoma, a Common Mesenchymal Tumor at a Rare Site: Emphasizing the Need for Awareness of Its Occurrence
}

\author{
Kiran Krishne Gowda, Raman Narayana Rao \\ Department of Laboratory Medicine, NU Hospitals, Bangalore, India \\ Email: kicha.doc.2k@gmail.com
}

Received 8 December 2014; revised 25 December 2014; accepted 6 January 2015

Copyright (C) 2015 by authors and Scientific Research Publishing Inc.

This work is licensed under the Creative Commons Attribution International License (CC BY). http://creativecommons.org/licenses/by/4.0/

\section{c) (†) Open Access}

\begin{abstract}
Leiomyoma is a benign tumor of smooth muscles. Leiomyoma originating from the scrotum is a rare entity. We report a case of 53-year-old African male who presented with a $3 \mathrm{~cm}$ lump in the right side of scrotum. Clinically, it was provisionally diagnosed as sebaceous cyst and was excised. The histopathology showed a leiomyoma. There was no cytological atypia or mitosis. The patient also had squamous papilloma over left gluteal region.
\end{abstract}

\section{Keywords}

Leiomyoma, Scrotum, Genital Leiomyoma

\section{Introduction}

Leiomyomas are benign tumors that originate from smooth muscles cells. Cutaneous leiomyoma are of three types: 1) tumors of arrector pili muscle (piloleiomyoma), 2) tumors of smooth muscles of blood vessels (angioleiomyoma), and 3) genital leiomyoma (from the smooth muscles of nipple, vulva, and scrotum) [1]. The genital leiomyoma arises from the diffuse network of smooth muscle in deep dermis of genital zones. In the scrotum, they arise from the dartos smooth muscle (dartoic leiomyoma) and in the nipple from the muscularis mamillae and areolae. This form is nearly always solitary and rarely causes significant pain. Smooth muscle tumors of scrotum were first described by Forsters in 1858 and are reported to be extremely rare. Scrotal smooth muscle tumors arising from dartos smooth muscle can further be categorized as leiomyoma, atypical leiomyoma and leiomyosarcoma. Less than 50 scrotal leiomyomas have been documented in English literature [2]. Here, we re- 
port a rare case of a leiomyoma of the scrotum clinically suspected to be a calcified sebaceous cyst in an African male. We emphasize that, despite being rare, smooth muscle tumors should be in the differential diagnoses in any scrotal swelling.

\section{Case Report}

\subsection{Clinical Features}

A 53-year-old African male presented to our urology clinic with chief complaints of right sided painless testicular swelling and swelling over left gluteal region since two years. He was diagnosed with hypertension and diabetes two years back and was on intermittent therapy for the same. Physical examination revealed a pedunculated firm lesion approximately three $\mathrm{cm}$ in diameter, on the right side of the scrotal sac. Bilateral testes were unremarkable. Inguinal lymph nodes were not palpable. In addition, a skin tag measuring $0.8 \times 0.5 \times 0.5 \mathrm{~cm}$ was noted over the left gluteal region. Systemic examination did not reveal any abnormality.

Laboratory investigations revealed normal haematological and biochemical parameters except for raised LDL ( $218 \mathrm{mg} / \mathrm{dL}$; normal < $130 \mathrm{md} / \mathrm{dL}$ ) and HbA1C (6.6\%; normal < 6\%). Renal function tests were within normal limits.

With a clinical possibility of calcified sebaceous cyst, patient underwent excision of the scrotal lesion along with that of the papilloma over left gluteal region. The postoperative course was uneventful.

\subsection{Histopathology}

Macroscopic examination of swelling in the scrotum revealed a firm, well circumscribed lesion measuring $3 \mathrm{~cm}$ in diameter, which on cut surface was solid, white with whorling. No necrosis or hemorrhage was noted. Microscopy confirmed a well circumscribed tumor arising from dartos (Figure 1). The tumor cells were arranged in short intersecting fascicles. They were monomorphic, had spindle shaped nuclei with blunt ends and eosinophilic cytoplasm. No mitotic activity, nuclear atypia or necrosis was noted. Focal areas of hyalinization (10\% of the total area) were noted. However, no calcification was identified. On immunohistochemical staining the tumour cells showed cytoplasmic positivity with smooth muscle actin (SMA) (Figure 2) and desmin confirming their smooth muscle differentiation and were negative for S-100. Ki-67 proliferation was $<5 \%$. The scrotal lesion was thus diagnosed as leiomyoma.

Skin tag on microscopy showed hyperkeratosis, orthokeratosis and papillomatosis of the stratified squamous

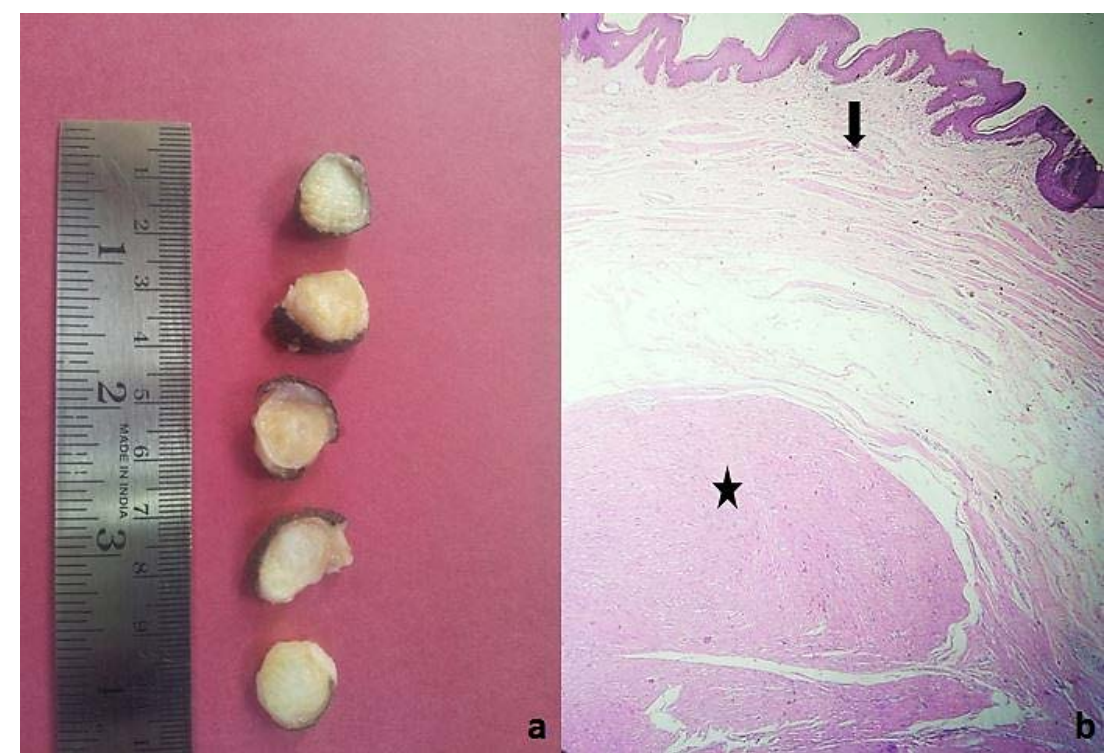

Figure 1. (a) Gross photograph showing cut surface of the well circumscribed tumor with solid white surface and areas of whirling; (b) Microphotograph showing well circumscribed tumor (star) well delineated from the skin and dartos (arrow) (H \& E, $\times 100)$. 


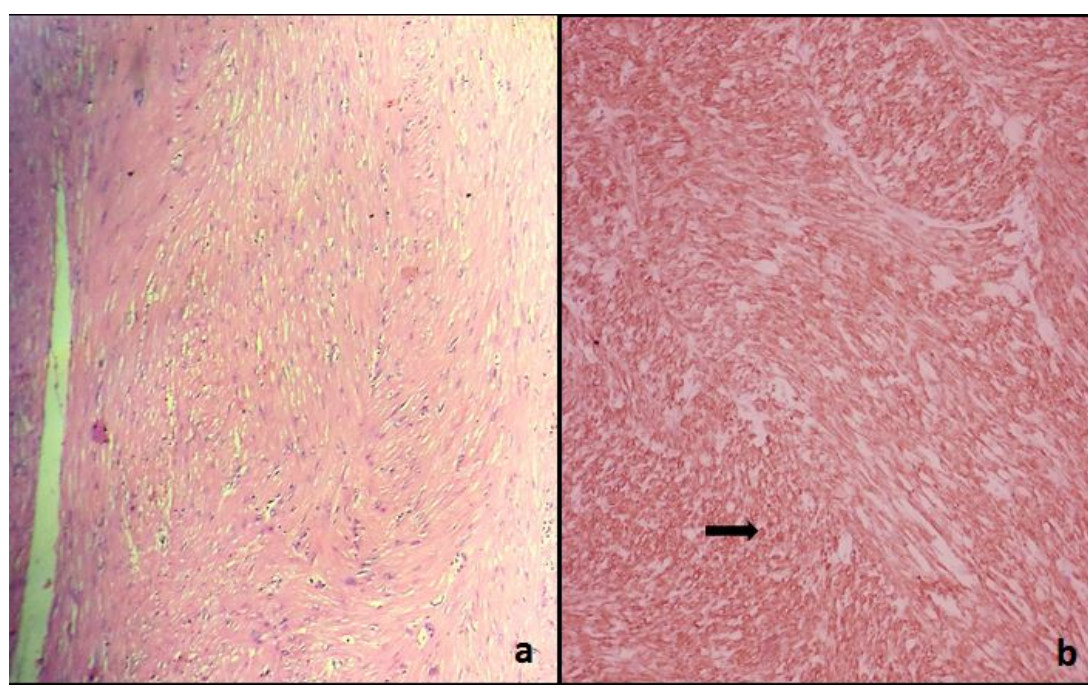

Figure 2. Panel of photomicrographs showing interlacing fascicles of smooth muscle bundles ((a): H \& E, ×400), which show cytoplasmic expression (arrow) of smooth muscle actin on immunohistochemistry ((b): SMA, $\times 400)$.

lining epithelium. However, no koilocytosis, dysplasia or malignancy was noted. Features were of squamous papilloma.

\section{Discussion}

Leiomyomas are benign tumours orginating from smooth muscle cells. Leiomyoma of skin and subcutaneous tissue can be divided into cutaneous (Pilar) leiomyoma, genital leiomyoma, or more deeply situated angioleiomyoma (vascular leiomyoma). Among the genital leiomyoma, which include those involving scrotum, vulva, or nipple, the leiomyoma of scrotum and vulva are clinicopathologically quite different, receiving little attention in the literature.

Scrotal leiomyoma is a rare tumor with $<50$ cases reported worldwide [2]. It occurs most often in white men between fourth and sixth decades of life, with most of the patients presenting with painless solitary small cutaneous lesion measuring $1-14 \mathrm{~cm}$ with the average of $6.4 \mathrm{~cm}$ [1]. Clinically, the differential diagnosis includes a sebaceous cyst, fibroma and schwannoma. Because of the asymptomatic, painless, and slow growing nature of the tumor, patients usually present late with an average of 7.6 years between the patient's recognition of the tumor and its surgical removal [3]. The patient in the current study was a black African from Nigeria, who presented within two years of lump recognition. This was more due to inquisitive nature of the patient rather than rapidity of growth of the lesion or any other symptomatology.

Four histopathological features are used to grade the scrotal smooth muscle tumours that include 1) size $\geq$ five $\mathrm{cm}$ in greatest dimension; 2) infiltrating margin; 3) $\geq$ five mitotic figures per 10 high-power field and 4) moderate cytological atypia. Tumours with only one of the above-mentioned features are considered benign and those fulfilling two of the criteria are diagnosed as atypical leiomyomas while tumours showing three to four of these criteria are leiomyosarcomas [4]. The tumor in the current patient was of three $\mathrm{cm}$ in greatest dimension, was well circumscribed with no atypia or mitosis. Ki-67 proliferation index was $<5 \%$. Hence, a diagnosis of leiomyoma is more likely in the current case, rather than atypical leiomyoma or STUMP (Smooth Muscle Tumor of Uncertain Malignant Potential).

Immunohistochemistry plays a vital role in determining the nature of spindle cells and conferring a final diagnosis. The tumour cells showed cytoplasmic positivity for SMA and were negative for S100 protein, determining their smooth muscle nature. Myofibroblasts also express SMA. In contrast to the uniform cytoplasmic expression of SMA seen in smooth muscle cells like in our case, myofibroblasts show expression of SMA only at the periphery of their cytoplasm ("tram-track" pattern). Other markers used to demonstrate smooth muscle differentiation include desmin, and caldesmon. But calponin and smooth muscle myosin are also occasionally used for this purpose. Cytoplasmic staining is observed in smooth muscle cells with all of these markers, al- 
though staining for one or more of them can be lost in poorly differentiated leiomyosarcomas.

Conventional leiomyomas and atypical leiomyomas behave in a similar fashion [5]. Hence, they are managed with excision while leiomyosarcomas require a wider resection with a three to five $\mathrm{cm}$ margin, including the subcutaneous tissue and fascia and negative margins. While excision is curative for leiomyoma, a close clinical surveillance of patients with an atypical leiomyoma is essential.

\section{Conclusion}

This case analysis highlights the rarity of leiomyoma in the scrotum, emphasizing two very important things. First, the clinician should be aware of occurrence of this benign smooth muscle lesion in the scrotum, to clinically suspect its presence. Second, leiomyoma must be distinguished from atypical leiomyoma and leiomyosarcoma, as the management of the latter two differs from that of leiomyoma. Atypical leiomyoma needs close surveillance post-excision, while leiomyosarcoma requires wider margin of excision and close surveillance postexcision.

\section{Acknowledgements}

We would like to thank our institute NU Hospitals, Bangalore for encouraging us to do the case analysis. Our special thanks to Dr. Venkatesh Krishnamoorthy, Dr. Prasanna Venkatesh, Dr. Maneesh Sinha and Dr. Pramod. $\mathrm{K}$, Urologists of NU Hospitals, Bangalore for their clinical inputs and participation in the patient care.

\section{References}

[1] Newman, P.L. and Fletcher, C.D. (1991) Smooth Muscle Tumours of the External Genitalia: Clinicopathological Analysis of a Series. Histopathology, 18, 523-529. http://dx.doi.org/10.1111/j.1365-2559.1991.tb01479.x

[2] Sherwani, R.K., Rahman, K., Akhtar, K., Zaheer, S., Hassan, M.J. and Haider, A. (2008) Leiomyoma of Scrotum. Indian Journal of Pathology and Microbiology, 51, 72-73. http://dx.doi.org/10.4103/0377-4929.40405

[3] Siegal, G.P. and Gaffey, T.A. (1976) Solitary Leiomyoma Arising from Tunica DartosScroti. Journal of Urology, 16, 69-71.

[4] Ragsdale, B.D. (2009) Tumours with Fatty, Muscular, Osseous Tissue and/or Cartilaginous Differentiation. In: Elder, D.E., Elenitsas, R., Johnson, B.L., Murphy, G.F. and Xu, G., Eds., Lever's Histopathology of The Skin, 10th Edition, Lippincott Williams \& Wilkins, Philadelphia, 1080.

[5] Rao, S., Fimate, P., Ramakrishnan, R. and Rajendiran, S. (2012) Atypical Leiomyoma of Scrotum. Journal of Cutaneous and Aesthetic Surgery, 5, 216-217. http://dx.doi.org/10.4103/0974-2077.101397 
Scientific Research Publishing (SCIRP) is one of the largest Open Access journal publishers. It is currently publishing more than 200 open access, online, peer-reviewed journals covering a wide range of academic disciplines. SCIRP serves the worldwide academic communities and contributes to the progress and application of science with its publication.

Other selected journals from SCIRP are listed as below. Submit your manuscript to us via either submit@scirp.org or Online Submission Portal.
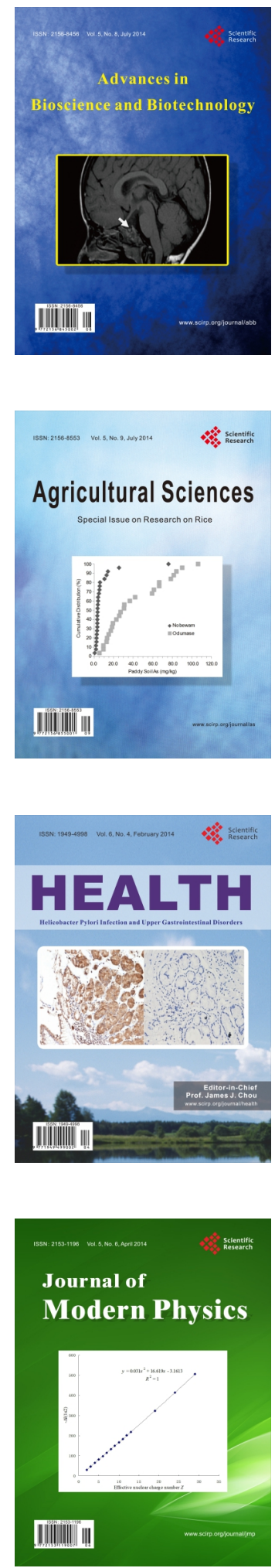
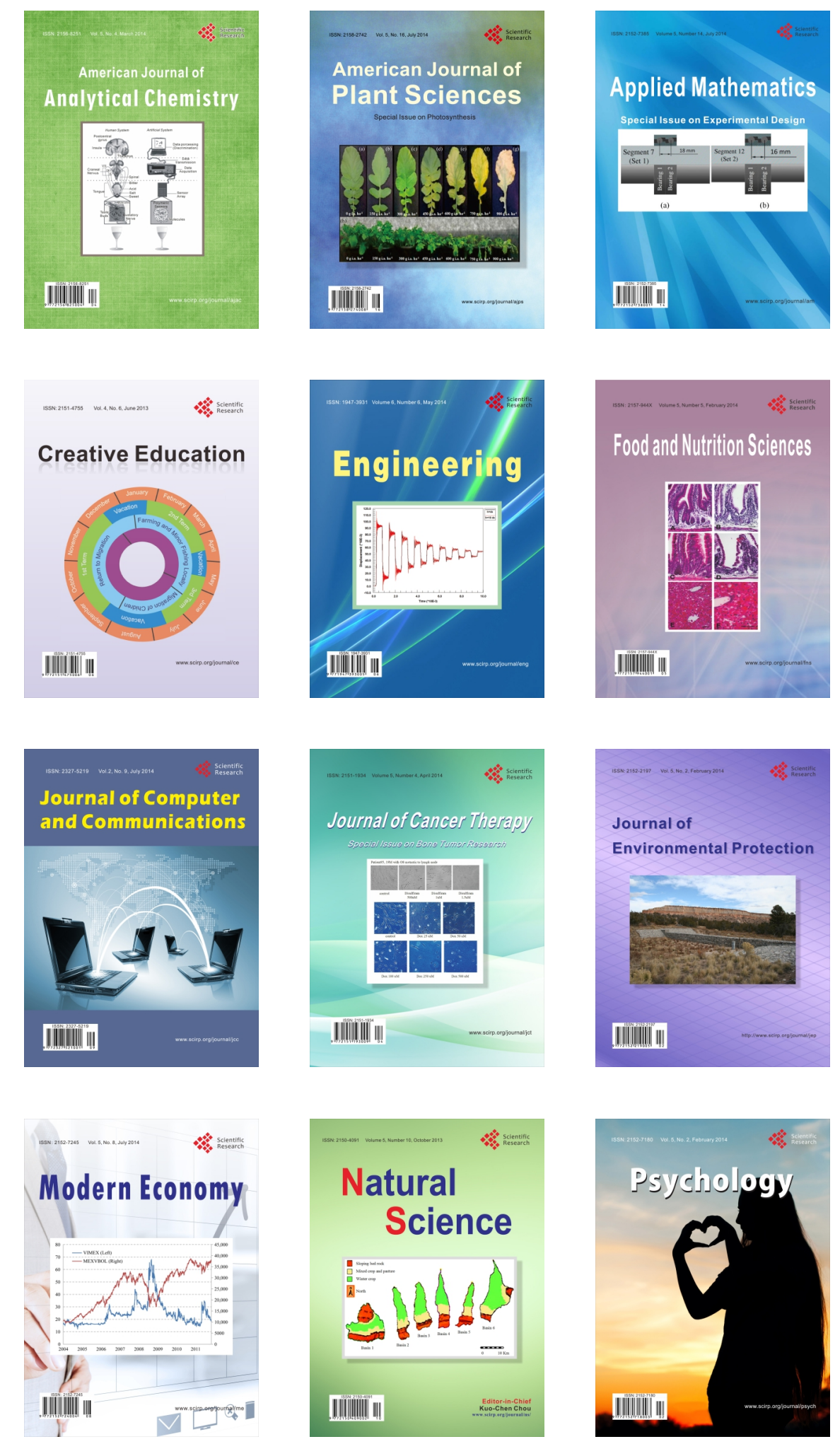